Vanda Pantoja

Doutoranda em Antropologia Social

PPCS-UFPA

\title{
MAUÉS, RAYMUNDO HERALDO \& VILLACORTA, GISELA MACAMBIRA. PAJELANÇAS E RELIGIÕES AFRICANAS NA AMAZÔNIA. BELÉM: ED. UFPA, 2008.
}

O livro Pajelanças e Religiôes Africanas na Amazônia, publicado em 2008, é resultado do Seminário "Pajelança e Encantaria Amazônica", realizado em 2002, pelo grupo de pesquisa, Simbolismo, Religiāo e Saúde da Universidade Federal do Pará - UFPA. Temas específicos como saúdelcura, gênero e imaginário, o que não excluem discussóes mais amplas como mercado religioso e pluralismo religioso, são discutidos por antropólogos, especialista de outras áreas e sacerdotes do campo afro. Os organizadores são os antropólogos e professores da UFPA Raymundo Heraldo Maués e Gisela Macambira Villacorta, ambos estudiosos do tema discutido. O livro, publicado pela Editora da UFPA, trás vinte artigos divididos em seis partes: I - Encantaria Brasileira: as "outras" religiōes afro-brasileiras, uma espécie de introdução ao tema, onde se privilegia a dimensão do sincretismo, assunto que acompanhará as temáticas que seguem; II - Pajelança e Encantaria Amazônica, onde os cinco artigos transitam por abordagem sobre cura e sincretismo; III - Religiōes afro-brasileiras: o Maranhão e o Pará, com quatro artigos que tratam sobre o sebastianismo e o tambor de mina; IV - Religióes Afro-brasileiras: umbanda e candomblé, onde um dos cinco artigos que o compóe retoma o tema da cura, além de textos que tratam da introdução e desenvolvimento das religiōes afro em contextos específicos; $\mathrm{V}$ - Gênero e Pajelança na Amazônia, trás imaginário e gênero como pontos de partidas nos três textos que o compóe; e finalmente a VI parte - Encantados, Encantarias e Encantamentos na Amazônia, onde se discute, em dois textos, imaginário e mudança cultural.

O livro inicia com $A$ dança dos caboclos: uma sintese do Brasil segundo os terreiros afro-brasileiros de Reginaldo Prandi, sociólogo da Universidade de

Debates do NER, Porto Alegre, ANo io, N. I6, P. 247-254, JUl./Dez. 2009 
São Paulo. Prandi parte da clássica noção de que o Brasil é um país mestiço formado por brancos, negros e índios e diz que processo semelhante se dá com a constituição das religiôes de matriz africana no Brasil, pois ainda que as mesmas sejam de inspiração africana incorporaram influências dos cultos europeus assim como daqueles nativos do Brasil. Importante menção é feita pelo autor à questão do contexto espacial ao enfatizar que os variados tipos de candomblés, a umbanda e a encantaria, se organizaram e se expandiram, absorvendo características dos lugares onde se desenvolveram. Mas a mestiçagem para o autor não se encerra apenas na capacidade que as religióes têm de incorporar símbolos e rituais de outras religiōes em seu repertório religioso, mas, sobretudo pela capacidade das mesmas em acompanhar as novas necessidades que se colocam às diversas formas religiosas no atual contexto de intenso pluralismo religioso.

$\mathrm{Na}$ segunda pare do livro o historiador Aldrin Moura de Figueiredo, professor da Universidade Federal, do Pará introduz o tema da cura na pajelança, mesmo não sendo este o foco central do texto Assim como eram os gafanhotos: pajelança e confrontos culturais na Amazônia no início do século $X X$. Nesse se discute os diferentes usos das concepçóes de linguagem sobre a medicina e a cura na Amazônia daquele período. Seu texto chama atenção para as correspondências entre a medicina ocidental e a medicina tradicional, particularmente aquela realizada por pajés que, pensadas como excludentes, muitas vezes se cruzavam através das práticas de cura da lepra, uma doença que foi um verdadeiro flagelo na Belém do início do XX.

O tema da cura na pajelança é foco central no texto discutido pelo antropólogo e professor da UFPA Raymundo Heraldo Maués. A pajelança cabocla como ritual de cura xamânica, além das questôes relativas à terapêutica chama atenção para a prática da pajelança como um fato social total que tem implicaçôes na vida como um todo das populaçóes caboclas da Amazônia. No mercado da cura o autor nos mostra que o pentecostalismo católico e protestante também se faz presente nas cidades amazônicas o que pode trazer fortes implicaçôes para a prática da pajelança tendo em vista a associação, no discurso pentecostal, de entidades da pajelança com agentes demoníacos.

Os textos da antropóloga e professora Gisela Macambira Villacorta e de Vicente Salles, sociólogo e um dos mais importantes estudiosos da cultura

Debates do NER, Porto Alegre, ano io, N. 16, P. 247-254, JUl./DeZ. 2009 
popular, chamam a atenção para a questão da bricolagem e da mestiçagem, respectivamente, presentes na pajelança. Ela discute as Novas concep̧̧ôes sobre pajelança na Amazônia (Nordeste do Pará) na qual há um forte componente ecológico que se apresenta no discurso das pajés por ela pesquisadas. Essa "pajelança ecológica" seria o resultado de vários processos de bricolagem surgidos a partir das influências de outras formas religiosas como Espiritismo kardecista, umbanda, pajelança, esoterismo e Nova Era, mas que preserva o xamanismo no centro dessa "mistura", já que a cura seria o objetivo final da prática xamânica. Vicente Salles, na Metamorfose da Ave se debruça sobre as variaçóes semânticas e sintáticas do temo tanguru-pará, um mito, que ao migrar para a encantaria se torna tango-do-pará. Trata-se de um texto que tem como centro o tema das circularidades culturais entre diferentes campos.

O tema das circularidades apontado nas entrelinhas do texto de Vicente Salles é anteriormente discutido pela ótica da flexibilidade cultural no texto Distribuição e heterogeneidade no complexo cultural da "pajelança do antropólogo Didier de Laveleye. Essa flexibilidade permite que "existam tantas pajelanças quantos povos diferentes existem no Norte do Brasil”, mas contribui, por outro lado, para a não existência de uma identidade "pajeistica" e mesmo para a não utilização do termo pajelança por seus praticantes. Isso resulta, na visão de Laveleye, no não posicionamento da pajelança no mercado dos bens simbólicos, dado a falta de uma figura/autoridade capaz de catalisar para si esta função. O autor afirma de acordo com Prandi (2001), que cada pajé tem uma total autonomia ritual e mísdoente. Agindo de forma autônoma os pajés escapam, segundo o autor, a uma caracterização geral acerca da pajelança ao mesmo tempo que se submetem à complexidade da própria sociedade brasileira.

As colocaçóes finais do autor contribuem para pensarmos a pajelança como uma prática que também se posiciona no mercado de bens simbólicos, mas a sua maneira, onde a credibilidadelautoridade do pajé, enquanto agente autônomo e não institucional, estaria diretamente relacionada à aprovação da demanda dos fiéis, tema bastante caro à sociologia preocupada com as questôes do Mercado Religioso.

Anaíza Vergolinho-Henry, pesquisadora e professora da UFPA, nos trás uma etnografia sobre a inauguração de um monumento em homenagem ao encantado Rei Sebastião numa cidade do interior do Pará. Todo o aparato

Debates do NER, Porto Alegre, ano io, N. I6, P. 247-254, JUl./Dez. 2009 
de infra-estrutura e ritualístico é descrito pela autora em Um encontro na encantaria: notas sobre a inauguração do "Monumental Mistico Rei Sabá". Ainda com foco na discussão sobre o encantado Rei Sebastião, mas dessa vez no Maranhão, Madian de Jesus Frazão Pereira, antropóloga e professora da Universidade Federal do Maranhão, em A encantaria e o "os filhos rei Sebastiāo", percorre o caminho das crenças e mitos que cercam a Ilha dos Lençóis naquele estado, entendida por seus habitantes como um lugar fantástico por ser uma das moradas do encantado "El Rei Dom Sebastião". A grande incidência de albinos na Ilha contribui para a construção de um imaginário lendário acerca da mesma já que estes se crêem descendentes de Dom Sebastião.

O Tambor de Mina é apresentado por Mundicarmo Ferretti, antropóloga e professora da Universidade Estadual do Maranhão e Sérgio Ferretti, antropólogo e professor da Universidade Federal do Maranhão, em dois textos distintos, mas que convergem na discussão. A mina maranhense, seu desenvolvimento e suas relaçôes com outras tradiçōes afro-brasileiras, da antropóloga, trata de definições e diferenças no universo das religiôes afro, com particular ênfase no Tambor de Mina do Maranhão. A autora aponta a diversificação dos terreiros de mina como fator que dificulta sua definição. Sergio Ferreti mostra as características da Mina enfatizando sua relação com o catolicismo em $O$ culto e as divindades do Tambor de Mina no Maranhão. Ambos os autores concordam que, por questóes de tradição, a transmissão dos saberes nesse campo religioso é bastante precário, isso faz com que os terreiros de Mina fundados por africanos se encontrem em declínio, fato que não acontece com os novos terreiros fundados por brasileiros que se encontram em processo de expansão.

$\mathrm{Na}$ quarta parte do livro, a cura já debatida em textos anteriores, é retomada no contexto da umbanda pela antropóloga Maria Helena Villas Bôas Concone, professora da Pontifícia Universidade Católica de São Paulo, no artigo Cura e visão de mundo. Numa escrita bem argumentada a autora se posiciona de forma contrária ao pensamento comum na área da saúde de que a procura por cura nos espaços de religião afro tem como justificativas falta de instrução, baixa escolaridade, ignorância, e desinformação por aqueles que a procuram. Sua opinião vai de encontro ao pensamento segundo o qual há uma cisão, no contexto das terapias populares, entre corpo e alma/espírito,

Debates do NER, Porto Alegre, ANo io, N. 16, P. 247-254, JUl./Dez. 2009 
cisão esta evidenciada pela suposta separação entre "doenças da medicina" e "outros males ou doenças" no campo da umbanda. A autora refuta as construçóes que afirmam um refluxo das medicinas populares que estariam, assim, reduzidas ao nicho das "coisas do espírito", seu argumento é de que a busca por soluções terapêuticas na Umbanda não se dá apenas por "despossuídos" e que a umbanda não é mais uma alternativa no rol dos sistemas terapêuticos, mas uma solução concomitante à medicina ocidental, um reforço.

A busca na Umbanda como uma terapêutica concomitante e não apenas alternativa às outras formas de tratamento pode ser entendida pela "cosmovisão" convergente que há no universo da umbanda e na sociedade de mofo geral a respeito de pelo menos dois pontos que a autora destaca: a concepção relacional de mundo natural e sobrenatural, o que implica a influência entre ambos, e a noção de unicidade entre corpo e alma, o que implica que qualquer problema que atinja uma pessoa, a atinge em sua totalidade.

Os três textos que seguem, tratam do processo de introdução e desenvolvimento do candomblé e umbanda em diferentes contextos espaciais. De maneira geral apontam uma característica comum: a capacidade dessas religiōes se adaptarem aos locais aonde chegam absorvendo características de formas religiosas presentes nesses locais. Os textos também chamam atenção para os aspectos distintos de uma pluralidade de formas religiosas, que aos olhos do censo comum parecem "a mesma coisa". Tais distinçôes não dizem respeito apenas às nomenclaturas relativas aos cultos nos diferentes lugares onde se manifestam, mas, sobretudo à ritualística dos mesmos.

O babalorixá e sociólogo Armando Vallado no texto $O$ candomblé de caboclo na Metrópole trata da origem, desenvolvimento e influências de cultos cristãos e de matriz afro no candomblé praticado na cidade como São Paulo. Pai Francelino de Shapanam, em O tambor de mina de encantaria em São Paulo e suas relaçóes com a umbanda e o candomblé conta um pouco da história da chegada, desenvolvimento, estabelecimento e influências de outras religiōes de matriz afro no Tambor de Mina em São Paulo, culto que chegou à capital paulista em 1977 com a fundação de sua Casa.

Na mesma trilha dos dois textos anteriores Marilu Márcia Campelo, antropóloga e professora da UFPA, no texto Recontando uma história: a formação e a expansão do Candomblé paraense, traça a trajetória de introdução

Debates do NER, Porto Alegre, Ano io, N. 16, P. 247-254, JUl./Dez. 2009 
do candomblé no estado do Pará, com origem na década de 1970. O ultimo texto é da antropóloga Taissa Tavernard de Luca. A partir da noção de campo de Pierre Bourdieu, ela adentra o universo organizacional das religióes afro. Em O campo religioso afro-brasileiro em Belém, conta a história da criação e desenvolvimento das instituiçóes de caráter civil responsáveis pela organização e representação das variadas formas de religião afro no estado do Pará. O texto da autora mostra o universo das disputas por poder e prestígio no campo das religióes afro que, particularmente no Pará, diferentemente de outros centros de grande influência religiosa afro, buscam legitimidade pela via institucional através da formação de federações e associações, que, por agregarem legitimidade se constituem importantes lócus de disputa entre os grupos religiosos afro-paraenses.

A quarta parte do livro é dedicada ao tema do imaginário, Josebel Akel Fares, professora da Universidade do Estado do Pará, pesquisadora na área de comunicação e semiótica, em $A$ matintaperera no imaginário Amazônico, passeia pela mitologia amazônica acerca da Matintaperera. Seres invisíveis, voadores ou terrestres as Matintas são narradas por vários autores que se preocuparam em registrar essa personagem imaginária que, na forma humana ou como pássaro, é recorrente no imaginário das populações urbanas e caboclas da Amazônia, mas que enquanto representação mitológica tem raízes mais distantes localizadas no pensamento medieval europeu.

Também trabalhando com imaginário, Raymundo Heraldo Maués, partindo da noção de ambigüidade, analisa uma das lendas mais freqüentes no imaginário amazônico: a lenda do boto. $\mathrm{O}$ boto, animal mamífero, mas que vive nas águas, é entendido como um animal que foge à classificação comum dos peixes ou dos mamíferos, tornando-se, por isso, um ser ambíguo. Sendo esta a razão para tantas construçôes lendárias a seu respeito. Devido a essa ambigüidade é um animal impensável como alimento pelas populaçóes amazônicas, mas é, ao mesmo tempo, um símbolo sexual para homens e mulheres de forte valor. Como a professora Josebel, Maués argumenta que construções mitológicas a exemplo dessas acerca do boto, possuem linhas de contatos mais amplas e antigas que vem da Idade Média, e que tais elementos simbólicos fazem parte do pensamento mítico, presente em todas as sociedades e em todos os tempos, conforme Lévi-Strauss.

Debates do NER, Porto Alegre, ano io, N. 16, P. 247-254, JUl./DeZ. 2009 
Em 1975, levantando dados para sua dissertação de mestrado, Maria Angélica Motta-Maués esteve por quatro meses morando em Itapuá, pequena ilha no Nordeste Paraense; a autora estava preocupada em entender o "status das mulheres e implicitamente dos homens" na comunidade. Vinte e cinco anos depois a antropóloga Gisela Macambira Villacorta esteve na mesma localidade também coletando dados para sua dissertação de mestrado. No texto Matintapereras e pajés: gênero, corpo e cura na pajelança amazônica motivadas pelo que as autoras chamam de "retorno a campo" resolvem pensar a quatro mãos seus "achados de campo". Elas escolhem tecer tal texto elegendo o tema gênero/pajelança, visto ter sido esta uma questáo observada por ambas nas distintas estadas em campo, e por ser uma prática de reconhecida importância para as pessoas do lugar. Nesse "cruzar de campos" as autoras constatam que muita coisa mudou na comunidade nesse intervalo de vinte e cinco anos. A chegada da energia elétrica, da televisão, de outras formas religiosas como o pentecostalismo, tanto católico como pentecostal, alterou sobremaneira o cotidiano da comunidade. Contudo muita coisa permaneceu, a exemplo das relaçóes de gênero. As autoras concluem que no que refere à questão da presença da mulher no xamanismo "nossos estudos se encontram", pois o mesmo modelo encontrado por Mottta-Maués foi verificado também por Villacorta após mais de duas décadas. Nesse modelo, à mulher era negada socialmente a função de pajé, quando não, lhe era atribuído o estigma de bruxa, feiticeira ou matintaperera. Uma das explicações encontradas pelas autoras para tal comportamento repousa nas diferentes concepçóes acerca do corpo de homens e mulheres pelos locais, sendo o corpo feminino entendido como ambíguo e impuro e, por isso, perigoso.

A sexta e ultima parte do livro Encantados, Encantarias e Encantamentos na Amazônia trás dois textos, em principio distantes um do outro. $O$ primeiro do escritor, poeta e professor universitário João de Jesus Paes Loureiro retoma as discussões sobre imaginário apresentadas na quinta parte do livro. Em Olhar ontológico o poeta descreve a Amazônia como encantaria, como lócus privilegiado para a produção de tantos mitos, lendas, paisagens idéias, cores e sabores; lugar onde habitam seres mitológicos como a Boiúna, os Botos, as Amazonas, assim como as naçóes indígenas e caboclas. Como Amazônia de encantaria, é ilha de Bem-aventurança, distante e próxima, lugar onírico onde

Debates do NER, Porto Alegre, Ano io, N. 16, P. 247-254, JUl./Dez. 2009 
conflitos e infelicidades parecem não ter abrigo, ainda que se multipliquem, sutilmente finaliza com sua poética crítica.

Finalizando o livro Mário Brasil, músico e professor da Universidade de Brasília, em $A$ visão do terreiro no processo de mudança musical faz um estudo comparativo com o objetivo que demarcar as mudanças musicais que ocorreram nas doutrinas do Babassuê num intervalo de tempo de sessenta anos. Para tanto utiliza gravaçóes desses cantos realizados pela Missão de Pesquisas Folclóricas realizadas no ano de 1938 e as realizadas pelo autor em pesquisa recente.

\section{CONSIDERAÇÕES}

Difícil resenhar um livro que trata das Pajelanças e Religiōes Africanas na Amazônia, dada a amplitude de possibilidades que o tema permite. Mas a qualidade dos artigos, vinte ao todo distribuídos em 370 páginas, de escrita simples e clara permite que o livro seja lido tanto por leigos como por "iniciados" ou especialistas nos temas. A organização do livro em seis partes, que aqui preservei, se constitui mais um recurso didático e menos uma fronteira entre os temas discutidos já que estes se remetem ao longo do livro. Assim, temos reunido em um livro um pouco do repertório religioso de uma parte da Amazônia, particularmente no estado do Pará e Maranhão, mas não apenas, já que alguns textos têm como contexto a cidade de São Paulo. Sua importância é a de possibilitar que estudantes e pesquisadores interessados no tema possam utiliza-lo como fonte de pesquisa ou mesmo para aqueles que desejam conhecer como essas práticas se dão no Norte do Brasil.

Os textos escritos por pesquisadores acadêmicos da área da Antropologia e de outras áreas de estudo, por pesquisadores que transitam tanto no campo acadêmico como no campo religioso e por sacerdotes, permitem ao leitor, sob variados ângulos, uma compreensão mais holística da cultura numa parte da Amazônia a partir de sua dimensão religiosa.

Debates do NER, Porto Alegre, ANo io, N. 16, P. 247-254, JUl./DeZ. 2009 